\title{
METHODICAL APPROACHES TO EVALUATION OF EFFICIENCY OF FUNCTIONING OF INTEGRATION PROCESSES IN THE FOOD INDUSTRY
}

\section{Nataliia Yurchenko ${ }^{1}$}

DOI: https://doi.org/10.30525/978-9934-26-049-0-14

Abstract. The article summarizes the approaches to assessing the effectiveness of integration presented in the economic literature and tested in world practice, argues the feasibility of creating integrated structures, highlights the main conceptual approaches to qualitative assessment of the effectiveness of integration of economic entities, namely: approaches based on the environment; transaction cost theory; assessment of the achievement of competitive advantages; assessing the benefits of longterm business relationships; theories of financial management; assessment of the interaction of shareholders and managers. In order to ensure the efficient functioning of the food industry, prevent further decline of all its industries and to ensure the competitiveness of domestic products in domestic and foreign markets, it is necessary to move to an innovative type of development and diversify the products of the food industry. In modern conditions, diversification acquires a slightly deeper meaning and can be defined as a variety of activities of the enterprise in the production, financial and marketing spheres.

The strategy of diversification of agricultural enterprises, which consists of expanded specialization and activities, vertical integration, renewal of ties and new initiatives, in the crisis can ensure stable business results. It is believed that diversification provides: resource competitive advantages (advantages that increase the consumer effect associated with price characteristics), technological competitive advantages (advantages that are due to the availability and operation of mass production technologies), innovative competitive advantages (advantages that allow to provide updating of the nomenclature and range), partnership competitive advantages (advantages which are connected with formation of social, economic standards of

\footnotetext{
${ }^{1}$ Reseacher, Department of Economic Research, Institute of Food Resources of National Academy of Agrarian Sciences, Ukraine 
economic activity and their realization. Therefore it is extremely necessary to focus on research of methodical provisions by means of which it is possible to analyze diversification measures at the enterprises).

\section{Introduction}

The need for intensive creation and operation of integrated structures is due to current trends in the world economy. Objective preconditions for the concentration and merger of industrial and banking capital in Ukraine arose as a result of economic reforms, which resulted in a change in property relations and the creation of integrated structures, without which the existence of a modern market economy is impossible. Restructuring of the dairy industry on the basis of the formation of integrated associations is one of the key problems of reforming the domestic economy.

It should be noted that there is no comprehensive scientific and methodological apparatus for modern assessment of the effectiveness of integration of economic entities. In this regard, it is important to generalize the approaches presented in the economic literature and tested in world practice to assess the effectiveness of integration and the feasibility of creating integrated structures and adapting them to the conditions of the domestic economy. Existing approaches to assessing the effectiveness of integration of economic entities are divided into two groups - qualitative and quantitative (cost). However, it should be noted that such a division is quite conditional, because the conceptual and methodological approaches to assessing the effectiveness of integration are interdependent and require comprehensive application.

\section{Conceptual approaches to qualitative assessment of the effectiveness of integration}

Analysis of research and practice of well-known economists [1-5] allows us to identify the main conceptual approaches to qualitative assessment of the effectiveness of integration of economic entities, namely: approaches based on the analysis of the operating environment; transaction cost theory; assessment of the achievement of competitive advantages; assessing the benefits of long-term business relationships; theories of financial management; assessment of the interaction of shareholders and managers. These conceptual approaches to assessing the effectiveness of integration 
processes emphasize certain criteria for the effectiveness of integration and can be used to consider individual aspects of the subjects of integration processes, to assess the achieved competitive advantages and the nature of control in the integrated structure and more.

According to the quantitative approach to assessing the effectiveness of integration processes, the methodology includes the assessment of a number of indicators [6-10]:

- overall efficiency of the integrated association (total value of the group's assets, total sales (turnover) for a certain period, gross profit);

- financial results of the parent company and specific participants in the integrated structure (using traditional approaches to identifying the ratio of costs and results);

- efficiency of separate blocks of the integrated structure (financial, investment, operational, research, commercial and others);

- financial condition of industrial enterprises - members of the integrated structure (value of net assets, liquidity, financial stability, business activity, efficiency, efficiency of the integrated structure in the capital market, etc.).

To develop an integration strategy, it is first important to assess the effectiveness of the investment in the acquisition of the company, in other words, to analyze its investment attractiveness and objectively assess the market value. In the economic literature, the vast majority of methods for determining the value of business (blocks of shares) are grouped into three approaches: comparative, profitable and expendable, and within each there are different options and methods of calculation. However, the current methodology is developed only to assess the effectiveness of mergers and acquisitions in the form of classic provisions for valuing companies, and does not take into account the impact on the effectiveness of the integration of a set of external and internal economic factors.

In our opinion, it is important to further develop methodological tools for assessing the effectiveness and efficiency of integration processes of economic entities, which is to form a system of criteria for effectiveness and efficiency of integration processes of economic entities, taking into account indicators of functional, technological, economic, commercial, institutional, environmental, social and innovation efficiency, as well as quality indicators; substantiation of the main stages of implementation of the algorithm for assessing the effectiveness of integration; development of 
a set of measures to increase the effectiveness of integration processes of economic entities and recommendations for the effective implementation of these measures.

The scientific literature describes three models of return on investment:

- rectilinear (Ring model), this method is purposefully used when it is expected that the return of principal will be carried out in equal parts;

- annuity (Invud model). Use of this approach is expedient at full return of investments and reception from them of the corresponding profits;

- Hoskold's model. It is used in cases where the probable loss of part of the invested capital in the process of the transaction. Current income in this case is considered both as a return and as a return on investment.

In addition, when developing a set of performance criteria should take into account the analysis of the environment of the integrated structure; it is necessary to focus on comparing the characteristics of the functioning (or designed) integrated structure and other companies that are present in related markets, in particular in terms of technological level of production, adequacy of production capacity and balance of their individual elements.

The considered method of assessment of expediency, efficiency and effectiveness of integration interaction of economic entities represents the complex decision of a problem of increase of efficiency of integrated industrial structures in domestic economy. It can be applied both at the stage of integration planning, allowing to make reasonable and economically sound decisions, and in the process of functioning of the integrated structure, in order to develop measures to correct the shortcomings of the existing structure, business relationships or erroneous decisions made in the process of integrated structure.

During this process, you can identify the main and auxiliary activities of the enterprise, explore the range and range of policies, analyze the implemented and planned projects according to relevant criteria, and so on. Therefore, it is advisable to focus on the study of guidelines that can be used to analyze diversification measures in enterprises.

\section{Methods of analysis of diversification measures at food production enterprises}

To assess diversification, scientists use a variety of indicators. According to M. Korinko [11], the main criterion for the effectiveness of the diversification project is a positive result obtained as the difference 
between the discounted amount of income and expenses. To study the activities of a diversified enterprise, the author proposes to apply financial analysis using the data of the statement of cash flows. He justifies his position by the desire to assess the current and future capabilities of a diversified enterprise.

Methodology L. Shutenko [12] is that the calculation of the level of diversification of enterprises is associated with determining the significance of each activity (the share of income from the activity in the total income of the enterprise). In addition, the author calculates the prospects of each activity as the ratio of actual and planned income. Based on this indicator, institutional leaders decide on the feasibility of further development of all activities of the organization.

V. Kutovyi [13] emphasizes that the choice of the most optimal project for the implementation of diversification is based on the calculation of the following indicators: net discounted income, index of return on investment, the internal rate of return of the project; payback period of investments; indicator of the overall economic effect as a result of diversification, an indicator of the effectiveness of diversification.

To determine the risks and effectiveness of industrial diversification A. Guryanov [14] uses the portfolio theory of the investor. In his opinion, this method allows to form an optimal set of projects to diversify production according to the criteria of the highest efficiency and lowest risk. The implementation of this method is accompanied by the use of probability theory, ie the indicator of the efficiency of the enterprise is considered a random variable with the probability of its occurrence.

To analyze the effectiveness of the business entity calculate the mathematical expectation, standard deviation, covariance, which most fully reveal the essence of random variables. At the same time state certain conditions: equality of variance of zero means absence of risk and on the contrary with increase of variance of efficiency of activity of the enterprise there is an increase in risk.

B. Bolomchuk [15] developed a method for assessing the level and degree of affinity of diversification of industrial enterprises. The authors focused on the study of the level of horizontal, vertical diversification, as well as diversification of markets. Scientists also determined an integrated indicator of the level of diversification of the enterprise on the basis of such 
data on the value of marketable products, the number of economic activities according to the NACE.

The basis for identifying the level of diversification, namely vertical and horizontal, is the use of the entropy index. As noted by A. Kovalov [16], the entropy index aims to: determine how the industries in which the enterprise operates are interconnected; identify the total number of industries in which the company operates; to investigate the segmented distribution of net income from the sale of products of the economic entity.

The integrated indicator of the level of diversification of the enterprise (D) is calculated as follows:

$$
D=\sqrt[3]{D \rightarrow * D \uparrow * D s}
$$

Scientists use this developed technique to study the impact of indicators of the level and degree of affinity of diversification of activities on the economic and social efficiency of industrial enterprises [15]. As indicators of economic efficiency use the return on assets and the growth rate of production. The social efficiency of enterprises can be described by the following indicators: the growth rate of wages of employees per month and the number of employees. In addition, the level of diversification can not only affect these types of enterprise efficiency, but also others, such as investment, marketing, innovation efficiency and so on.

M. Minkovska believes that it is economically possible to assess the diversification of production using the investment approach. According to this approach, the main role is given to net present value (NPV). This indicator is aimed at assessing the effectiveness of industrial diversification. NPV is characterized by adaptability. This property makes it possible to form the total value of NPV, which includes the value of this indicator for different diversification projects. The generalized objective function is shown as follows [17]:

$$
N P V=\sum_{i=1}^{s} N P V i \rightarrow \max ,
$$

$\mathrm{i}=1 \ldots \mathrm{s}-$ projects that form the investment portfolio of the enterprise.

Quite often foreign multidisciplinary companies calculate the level of diversification using the most popular method of standard industrial classification code (SIC). The basis of this method is the industry 
classification system, ie distinguish between low and highest level of integration of industry areas. If a company is assigned a four-digit number, it means that its activities are related to only one industry.

The most diversified companies are marked by a single number of associations of industries [17]. In Ukraine, the level of diversification can be determined through the classifier of economic activities (NACE-2011). The main disadvantage of NACE-2011 is the irrational division into groups and classes of economic activities of enterprises. The most common indicators for a thorough analysis of the level of diversification are: absolute diversification index, transformed concentration index, Berry index, concentration ratio, degree of risk, entropy index, profit dispersion of the enterprise, Atton index [18].

In order to identify the degree of diversification of the enterprise, scientists consider it necessary to use the following indicators: 1) the absolute level of diversification - with this indicator you can identify all industry areas of the organization on the basis of calculating the share of primary production; 2) integrated indicator of production diversification calculated on the basis of the Herfindahl-Hirschman index:

$$
I_{h h}=1-\sum_{i=1}^{n} S_{i}^{n}
$$

where $S_{i}$ - fraction of the i-th industry in the overall structure of marketable products of the enterprise; $n$ - total number of industries.

3 ) the integrated indicator of production diversification is calculated using the coefficient of concentration of industries:

$$
I_{d}=1-\frac{100}{\sum_{i=1}^{n} S i *(2 N i-1)}
$$

$\mathrm{Ni}$ - the ordinal number of the branch (the branch with the largest value of specific weight is the first rank, otherwise the last) [19].

If the value of the calculated indicator is equal to 0 , then the company is specialized in the production of one type of product, if it reaches $1-$ the company can be considered diversified.

The degree of diversification of the enterprise can be analyzed on the basis of the methodological approach proposed by Richard Rumelt. The essence of this approach is to separate the interconnected centers of business activity of the enterprise (engaged in the production of certain types of 
products) by production and market areas of activity and provides for their autonomous management.

As a result, determine the relevant criteria for diversification of the enterprise and their relationship [20]:

- specialization (Ps) - a very important area of activity of the enterprise is the area that is characterized by the largest share of sales in total;

- the level of centralization of business success (Pc) - reflection of the share of investments in various areas of activity in the total income of the enterprise, which use competitive advantages, competencies, resources;

- the level of relationships (Pr) - determines the importance of interrelated activities of the enterprise;

- the level of vertical integration (Pi) - reflects the volume of use of raw materials, semi-finished products, as well as the receipt of products that are the result of production activities of the enterprise.

The relationship between these indicators is shown as follows:

$$
\mathrm{Ps} \leq \mathrm{Pi} \leq \mathrm{Pc} \leq \mathrm{Pr}
$$

Some foreign scholars to assess diversification offer eight main criteria, which are of a financial nature, to assess diversification: income (profit); time period; project risk; rights received by the new owner; liquidity; restrictions related to additional activities; advantages over competitors; alternatives for investment [21]. Each of these criteria can be used to understand whether diversification is effective for the company.

Diversified enterprises can be explored using portfolio analysis (Product Life Cycle Theory, BCG Matrix, McKinsey Method, ADL / LC Model, PIMS Model). The implementation of such a study will help diversified companies to effectively manage all types of business.

\section{Integrated method of diversification assessment}

The integrated method is often used in the analysis of diversification measures at enterprises. This is confirmed by the scientific works [21] proposed 5 groups of indicators to assess the effectiveness of enterprise diversification:

1) economic: liquidity, profitability, return on diversified production, relative release of working capital, payback period of investments as a result of diversification; 
2) strategic: cost-effectiveness of diversification strategy, the level of risk of each strategic management area, compliance with the mission and objectives of the enterprise;

3) market: the degree of effectiveness of advertising, increasing market share, access to new markets;

4) social: increasing the level of employment, reducing the turnover of labor resources, reducing the digital divide, the degree of consumer satisfaction;

5) technological: the level of savings in current costs, the degree of convergence, the degree of compliance of technology with modern requirements.

After that, the above indicators are integrated into a single indicator in the form of a weighted average.

In addition, the authors used Ryabtsev's method to develop a scale for evaluating the effectiveness of enterprise diversification. This scale is presented as follows: $0<\mathrm{Ef}<0.44$ - inefficient diversification, $0.45<\mathrm{Ef}<0.74-$ satisfactory diversification, $0.75<\mathrm{Ef}<0.89-$ effective diversification, $0.9<\mathrm{Ef}<1,0-$ the most effective diversification.

\section{Findings}

The generalization of research made it possible to systematize the indicators of effectiveness and efficiency of integration processes of economic entities. Each indicator of the system of assessment of the feasibility of integration is determined by the purpose of creating an integrated structure and is used to calculate the size of the corresponding advantage.

The financial indicator, which is taken as a basis for calculating the size of the advantage, depends on the nature of this advantage. Thus, if the creation of an integrated structure is aimed at increasing the competitiveness of enterprises involved in integration processes, and allowed to save on operating costs, then to assess the effectiveness of integration interaction, it is advisable to use projected net cash flow on invested capital.

In this case, the effect of increasing the competitiveness of enterprises that are part of the integrated structure is defined as an increase in net cash flow:

$$
\text { Vsynergy }=C N F i c-\sum_{i=1}^{n} C N F i,
$$


Vsynergy - synergistic effect;

$C N F$ - projected net cash flow on invested capital of the integrated structure;

$C N F i$ - projected net cash flow of the i-th company, obtained by operating outside the integrated structure $(i=1 \ldots, n)$,

$n$-the number of companies that are part of the integrated structure

When creating an integrated structure to maximize the return on invested capital based on the concentration of production, the synergy effect should be determined on the basis of increasing the return on equity of enterprises:

$$
\text { Vsynergy }=\text { ROEic }-\sum_{i=1}^{n} R O E i,
$$

$R O E i c$ - forecast return on equity of the integrated structure;

$R O E i$ - projected return on equity of the i-th company, obtained under the condition of carrying out activities outside the integrated structure $(i=1, \ldots, n)$.

If the integrated structure is created in order to increase production capacity and conquer new markets, the effect of synergy should be assessed on the basis of increasing net income (revenue) from sales of products (works, services):

$$
\text { Vsynergy }=\text { Sic }-\sum_{i=1}^{n} S i
$$

NCFis - forecast revenue from sales of products (works, services) of the integrated structure;

NCFis - forecast revenue from sales of products (works, services) of the i-th company, obtained under the condition of carrying out activities outside the integrated structure $(i=1, \ldots, n)$.

The synergy effect can be similarly determined when creating integrated structures in order to obtain other integration benefits.

In addition, the feasibility of integration can be determined based on the net reduced synergy effect (NPVS):

$$
N P V S=\sum_{t=1}^{T} \frac{\Delta F C F E t}{(1+r e)^{t}}-P-E
$$

$\triangle F C F E= \pm \Delta S \pm \Delta C \pm \Delta T+\Delta N W C+\Delta C a p e x \pm \Delta L+\Delta D e b t-I$, $N P V S$ (Net present value synergies);

$\triangle F C F E$ (free cash flow to the equity holders); 
$\Delta S$ (sales) - change in revenue from sales of products (works, services);

$\Delta C$ (costs), $\Delta T$ (tax), $\triangle N W C$ (net working capital) $\Delta$ Capex (capital expenditure);

$\Delta L$ (labor) - revenue growth (cost savings due to the combination of team management skills);

$\Delta D e b t$ - change in receivables (taking into account financial synergies);

$I$ - additional investments for internal integration and restructuring of the integrated association;

$r e$ - return on equity (discount rate), unit share;

$P$ - a premium paid by the initiator of integration to the owners (shareholders) of the target company;

$E$ (expenses) - the costs of the initiator of integration in the integration process.

The proposed method of assessing the feasibility of integration based on the net reduced synergy effect allows you to objectively take into account and evaluate the full range of forms of synergy effect (both quantitative and qualitative) and provides an opportunity to select and conclude only those agreements that are promising view of the feasibility of developing the integration of enterprises. It should be noted that the implementation of the proposed comprehensive methodology for assessing the feasibility, effectiveness and efficiency of integration of economic entities involves taking into account the following provisions: performance indicators should be considered in dynamics, aggregate and relationship to obtain a complete picture of integration when the effect of the implementation of one measure can be eliminated by the negative action of another.

When assessing the effectiveness of cooperation agreements, it is advisable to plan for a period of at least one year; associations (mergers or acquisitions) - for a period of at least five years; the development of integration should be accompanied by the creation of a common planning system and certain objectives for the participants of the integrated structure.

Mathematical methods for estimating synergetic effects use simulation modeling, self-organization models, logistic equations, neural network systems. There are also methods that equate the synergistic effect with the overall efficiency of the corporation. Thus, sometimes the synergetic effect is considered: as the sum of integrated indicators for assessing the relevant production, financial, customer potential of the trading company; as the 
sum of the efficiencies of the potentials of the subsystems of the economic unit, adjusted by the coefficient of the degree of influence of the potential of each subsystem on the synergetic efficiency of the economic system.

With stable cash flows from the joint activities of the post-integration company, the cost of synergy is calculated by the formula:

$$
V=\frac{C F}{R},
$$

$C F$ - the cash flow generated due to synergistic effects;

$R$ - capitalization rate. The capitalization ratio consists of two elements: the rate of return on investment; rate of return on investment.

According to all available methods of analysis of the effectiveness of diversification in enterprises, the following groups of indicators are identified: production, financial - economic, technological, resource and market [22-23]. Each of these groups covers certain indicators. The production group includes indicators that can be used to determine how diversified the company is, what amount of assets is needed to diversify, whether the productivity is significant in the implementation of diversification.

Financial and economic group of indicators for the analysis of diversification characterizes its effectiveness, investment. That is, the effectiveness of diversification is represented by the amount of profit from diversified products, the cost of diversified products. Diversification investment is reflected in the amount of long-term and current liabilities required for diversification, as well as the amount of equity involved in the diversification process.

The technological group of indicators it is possible to analyze the number of introduced new types of technologies in the implementation of diversification, the number of implementation of scientific developments as a result of diversification, introduction and disposal of fixed assets in the implementation of diversification. These indicators demonstrate the innovative activity of the entity in participating in diversification. With the help of a resource group of indicators, you can analyze the extent to which the company is provided with labor, raw materials, spatial, information resources. The market group of indicators reflects the marketing (market share of the enterprise, the number of satisfied consumers in the implementation of diversification), foreign economic efficiency (level of export and import activities) of the enterprise as a result of diversification. 


\section{Conclusions}

In conditions of constant change of the external environment, which is due primarily to the development of scientific and technological progress, deepening globalization of the world economy, intensification of competition, industrial enterprises seek to use effective ways to organize their activities. One such way is to diversify the activities of economic entities. The urgency of diversification in the food industry is due to the possibility of ensuring a high level of competitiveness in domestic and foreign markets, innovative development, increasing the level of efficiency in a market economy.

To ensure the effective development of diversification in enterprises, it is necessary to take into account the following characteristics: evolutionary, structured, multifaceted, comprehensive, focused, emergent, dynamic, synergistic, the presence of feedback.

Analysis of the implemented diversification is an important step for the company. During this process, you can identify the main and auxiliary activities of the enterprise, explore the range and range of policies, analyze the implemented and planned projects according to relevant criteria, and so on. Therefore, it is extremely necessary to focus on the study of methodological provisions that can be used to analyze diversification measures in enterprises.

\section{References:}

1. Ivanova O. (2002) Integration efficiency: evaluation methods,79 p.

2. Pleshchinsky A. (2004) Optimization of interfirm interactions and intrafirm management decisions, $252 \mathrm{p}$.

3. Reilly F. K. (2019) Investment Analysis and Portfolio Management: 6 ed. The Dryden Press, 446 p.

4. Banker R.D., A Charnes and WW Cooper (1984) Some Models for Estimating Technical and Scale Inefficiencies in Data Envelopment Analysis. Management Science, 30(9): 1078-1092.

5. Charnes A., Cooper W., Rhodes E.L. (1978) Measuring the Efficiency of Decision Making Units. EJOR, 2: 429-444.

6. Bohataia Y. (2001) Strategic accounting of the property of the enterprise, $320 \mathrm{p}$.

7. Galpin T.J. (2005) The Complete Guide to Mergers and Acquisitions: Methods and Procedures for Integration at all levels of the hierarchy, $237 \mathrm{p}$.

8. Gohan Patrick A. (2007) Mergers, acquisitions and restructuring of companies. Alpina Business Books, 741 p.

9. Grandi T. (2008) Mergers and acquisitions. How to prevent the destruction of corporate value by acquiring a new business, $240 \mathrm{p}$. 
10. Copeland T. (2002) Value of companies: assessment and management. Olymp-Business, $565 \mathrm{p}$.

11. Korinko M. (2007)Diversification:theoretical and methodological bases: monograph, $486 \mathrm{p}$.

12. Shutenko, L. (2004) Diversification of production activities of enterprises is the main direction of the exit of the Ukrainian economy from the crisis state on the way of its transformation to market relations. Municipal Economy of Cities, (54): 37-51.

13. Kutoviy V. (2009) Go to the assessment of the efficiency of diversification of the enterprise.Collection of Science Works Economic space, (24): 278-289.

14. Guryanov A., Sarikov A. (2005) Mathematical model of optimization of diversification of production. Communal services of cities, 144-151.

15. Bolomchuk B. (2009) The influence of diversification on the efficiency of the enterprise. Bulletin of the National Transport University, (19): 298-305.

16. Kovalov A. (2012) Strategy of diversification of industrial enterprises: monograph, $212 \mathrm{p}$.

17. Minkovska M. (2004) Management of diversified processes at enterprises of Ukraine: abstract of a dissertation on the level of candidate of economic sciences. National Academy of Sciences of Ukraine, Institute of Economics of Industry, $20 \mathrm{p}$.

18. Raduka N. (2011) Diagnostics of diversified processes at industrial enterprises. Strategy of the economic development of Ukraine, (29): 214-221.

19. Andriychuk V. (2002) Economics of agricultural enterprises: textbook. 2nd add., 624 p.

20. Otenko I. (2010) Analytical tools for risk assessment of strategic diversification. Business Inform, (12): 148-152.

21. Strelchuk E. (2014) Efficiency of diversification of telecommunication enterprise activity. Economics: realities of time, (2): 28-33.

22. Grigoruk P. (2012) Methods of building an integrated indicator. Business Inform, (4): 34-38.

23. Feshchur R. (2010) Economic and mathematical modeling: textbook, 340 p. 